Viso - Cadernos de estética aplicada Revista eletrônica de estética

ISSN 1981-4062

№ 3, set-dez/2007

http://www.revistaviso.com.br/
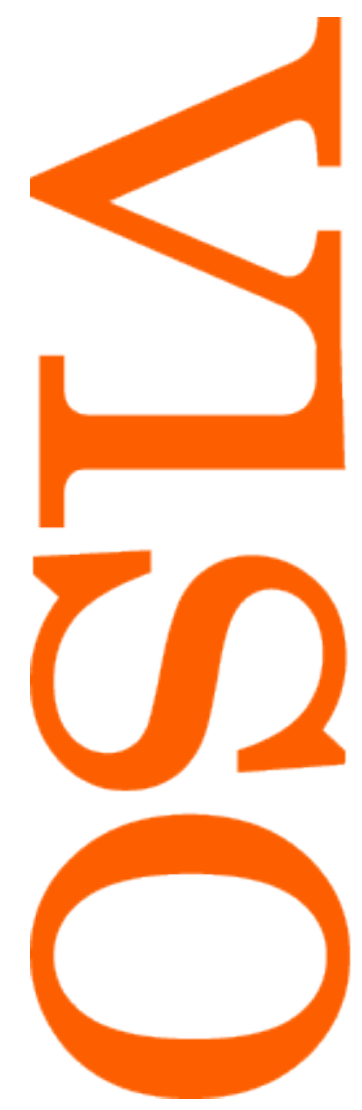

\title{
Francis Bacon sob o olhar de Gilles Deleuze: a imagem como intensidade Osvaldo Fontes Filho
}

Pontifícia Universidade Católica de São Paulo (PUC-SP) 


\section{RESUMO}

Francis Bacon sob o olhar de Gilles Deleuze: a imagem como intensidade

O ensaio de Gilles Deleuze La logique de la sensation é texto que se detém principalmente na prática e na eficácia da imagem. A pintura de Francis Bacon é ali tomada como paradigma de modernidade ao investir contra os clichês expressivos e ao produzir imagem junto à brutalidade dos fatos, como um contra-efeito do narrativo. Em uma obra que conjura todo modelo a representar, toda história a contar, "alguma coisa se passa", explica Deleuze, "que define o funcionamento da pintura". Algo se passa, tem lugar: o acontecimento de uma catástrofe e de uma histeria no ato de pintura que acomete a Figura de modo a transmitir uma potencial violência de reação e de expressão. O "Bacon" de Deleuze apresenta a realidade vivida em uma nova e nãoconvencional ordem de sensação.

Neste artigo, são comentados os modos como o filósofo interpreta os atos físicos da pintura de Bacon - marcas aleatórias, varredura da massa pictural, escansão das superfícies -, procedimentos que introduzem no mundo visual da figuração a variedade caótica dos fatos e sentidos. Mostra-se como as faces e as figuras contorcidas, distorcidas, escorchadas de Bacon recebem uma voz conceitual complementar no texto de Deleuze. Consequentemente, focaliza-se a disposição de alguns conceitos do filósofo: diagrama, Figura, diferença, espaço háptico. Locados no espaço afetivo ou na "lógica da sensação" da pintura baconiana, esses conceitos atribuem legitimidade ao entrelaçamento e à co-implicação entre arte e filosofia.

Uma última observação dá conta do fato de a prática da imagem em Bacon, apresentada por Deleuze no palco de uma modernidade particularmente solapada por um "dilúvio anestésico de imagens reprimindo a possibilidade de pensar", evidenciar para o filósofo os rumos necessariamente sinuosos, "reptilíneos", do pensamento moderno. Tanto o conceito como a forma criam por catástrofe, por conflagração, por variações alotrópicas.

Palavras-chave: pintura - intensidade - imagem - Gilles Deleuze - Francis Bacon 


\section{ABSTRACT}

Francis Bacon according to Gilles Deleuze: image as intensity

Deleuze's The Logic of Sensation> is mainly concerned with the practice and the efficacy of image. Francis Bacon's paintings are taken as a paradigm of modernity by their resistance to expressive clichés, their efforts to escape traditional narrative and by their ability to produce images as a result of the brutality of facts. In a work that deserts any model of representation, any history to be narrated, "something happens", claims Deleuze, "that shows how painting is really made". Catastrophe and hysteria within the act of painting overcome Figure so as to convey a potential violence of reaction and expression. Deleuze's Bacon presents the reality we live under the new and unconventional order of sensation.

This paper comments Deleuze's interpretation of physical acts in Bacon's painting random marks, sweeping and brushing motions, surface scansion - as techniques that introduce into the visual world of figuration a chaotic variety of facts and senses. Bacon's twisted, distorted, mangled faces and figures are shown as receiving a complementary conceptual voice in Deleuze's text. Therefore, we focus on some of the philosopher's concepts: diagram, Figure, difference, haptic space. Located within the affective space or the "logic of sensation" of Bacon's paintings, such concepts permits us to properly draw an intertwining and co-implication between art and philosophy.

On a final note, we observe that, presented by Deleuze as paradigmatic in a modernity assailed by an "anesthetic deluge of images impeding thought", Bacon's practice of image evidentiates to the philosopher the sinuous, "reptilinian" ways undertaken by modern thought. Both concept and image create through chaos, conflagration and allotropic variations.

Keywords: painting - intensity - image - Gilles Deleuze - Francis Bacon 
FONTES FILHO, O. "Francis Bacon sob o olhar de Gilles Deleuze: a imagem como intensidade". In: Viso: Cadernos de estética aplicada, v. I, n. 3 (set-dez/2007), pp. 70-90.

\section{$10.22409 / 1981-4062 / v 3 i / 48$}

Aprovado: 30.11.2007. Publicado: 27.12.2007.

(C) 2007 Osvaldo Fontes Filho. Esse documento é distribuído nos termos da licença Creative Commons Atribuição-NãoComercial 4.0 Internacional (CC-BY-NC), que permite, exceto para fins comerciais, copiar e redistribuir o material em qualquer formato ou meio, bem como remixá-lo, transformá-lo ou criar a partir dele, desde que seja dado o devido crédito e indicada a licença sob a qual ele foi originalmente publicado.

Licença: http://creativecommons.org/licenses/by-nc/4.0/deed.pt_BR

Accepted: 30.11.2007. Publicado: 27.12.2007.

(C) 2007 Osvaldo Fontes Filho. This document is distributed under the terms of a Creative Commons Attribution-NonCommercial 4.0 International license (CC-BY-NC) which allows, except for commercial purposes, to copy and redistribute the material in any medium or format and to remix, transform, and build upon the material, provided the original work is properly cited and states its license.

License: http://creativecommons.org/licenses/by-nc/4.0/ 
O que faz imagem em Francis Bacon parece ser o que justamente explica sua dissipação: uma intensidade que ela somente desvela ao se deixar ver como queda, consumição, indiscernibilidade. Gilles Deleuze, em Logique de la sensation, nos fala da pintura de Bacon em termos de uma energética: o contorno concentra ali um potencial de "desterritorialização" que o artista se encarrega de levar ao paroxismo. Assim, em seu processo de desorganização, a imagem anuncia que todo corpo que ela representa é possuidor de uma capacidade de negar a própria evidência narrativa.

Em uma obra que conjura todo modelo a representar, toda história a contar, "alguma coisa se passa", explica Deleuze, "que define o funcionamento da pintura". ${ }^{1}$ Algo se passa, tem lugar, o acontecimento de uma intensidade - que não é nem espetáculo, nem representação -, que se confunde com a construção mesma do lugar pictórico. Matter of facts nada estéticos (na acepção "belas-artes" do termo).

A seguir, são analisados brevemente os modos como Deleuze interpreta os fatos da construção baconiana de um lugar de escape do corpo-de-sensações - do que ali faz seu ritmo, sua modulação, seus espasmos -, lugar de sua inexorável desorganização, onde ele investe a figura paradigmaticamente moderna de uma carne informe.

Sabe-se como em Deleuze os conceitos são reportados a circunstâncias, não mais a essências, o que explica seu preconizado "atletismo": ao longo de linhas de devir, os conceitos devem se compor em variedade caótica. De modo que, intérprete dos corpos pulsionais de Bacon, interessa-lhe mostrar como no pintor a forma perde poder de informação para ganhar o registro dos acasos e dos acidentes: de-formação. A imagem se faz informal porque produzida por sua própria deperdição enquanto ilustração. Assim se apresentando no palco de uma modernidade particularmente saturada de clichês, a imagem, ao sabor da histeria baconiana, evidencia para o filósofo os rumos necessariamente sinuosos, "reptilíneos", do pensamento moderno.

Inicialmente, cumpriria perguntar pela pertinência de exigir da filosofia, essa grande desmemoriada das práticas, uma contribuição de peso ao embate com a questão "o que faz imagem?". Ora, se Deleuze se presta a tal, é porque sua filosofia entende ser uma conversão da teoria à prática, transformando a teoria em interrogação. Ela pode e deve se constituir como teoria do que se faz, e não como teoria do que é, pois o pensamento somente diz o que é ao dizer o que faz. Razão porque em Deleuze vêem-se aproximadas as questões "o que faz imagem?" e "o que faz pensamento?".

Mas seria o mesmo modus operandi que propõem uma e outra? Poderíamos assumir que haveria uma imagem do pensamento e um pensamento da imagem que se equivaleriam, que valeriam um pelo outro? Em outras palavras: que valor atribuir a um questionamento filosófico acerca do fazer imagem na arte? Qual seu interesse, sua 
necessidade, sua importância - para empregarmos a parametria que o interrogar deleuziano propõe para o pensamento moderno?

Essas indagações têm razão de ser: a filosofia já se mostrou em várias oportunidades equivocada quando da expressão da prática artística, da análise do que faz imagem, de como ela é feita, do que ela faz. A esse respeito, La vérité en peinture de Derrida, com sua complacente tortuosidade hermenêutica, não parece constituir caso único. Deleuze, em particular, receia contribuir à grande tagarelice reinante (que ele continuamente denuncia) onde tudo quanto seja do registro do fazer invariavelmente se ausenta do conceito. De fato, ele nos alerta ao ruído comunicacional ambiente, um excesso de solicitação a comunicar que é um perfeito impedimento ao ato de pensar. As forças e poderes atuais nos impedem de pensar na exata medida em que nos apanham na comunicação como sistema circulatório das informações, das significações dominantes. Como pensar quando a realidade substituiu o pensamento pela informação e por um patético simulacro midiático do ato pensante como prova pública das opiniões, fixação de consensos críticos, racionalidade comunicativa ou conversa produtora de novas significações dominantes? Que aventuras haveria ainda viáveis para o Conceito, pergunta-se Deleuze, quando o mundo atual cristalizou impossibilidades inéditas, uma terrível crispação dos possíveis? Se as idéias se perfilam como um imenso dispositivo de comunicação, compete à filosofia descomunicar, introduzir curtos-circuitos na comunicação, combater seus universais, propor conceitos como operadores anticomunicativos. "Criar vacúolos de não-comunicação, interruptores, para escapar ao controle". 2

É porque o filósofo não faz mais que enriquecer o que se tem a dizer, variar suas condições, acrescentar-lhe nexos insuspeitos, que Deleuze entende ser necessária à filosofia uma compreensão não-filosófica. "A filosofia está numa relação essencial e positiva com a não-filosofia [a pintura entre outras]: ela se dirige diretamente aos nãofilósofos". ${ }^{3}$ Mesmo porque "a comunicação vem sempre demasiado cedo ou demasiado tarde e a conversa está sempre a mais, em relação a criar". ${ }^{4}$

Insista-se nessa relação essencial e positiva com a não-filosofia. Pensar, na sua impostação (deleuzianamente) filosófica, significa: singularizar, inventar conceitosacontecimentos capazes de desfazer as relações estabelecidas entre os seres e de conceber outras, de relançar possibilidades, de calar as respostas e de fazer falar novos problemas. Eis o que aproxima o filosofar do criar: possíveis que suscitem novos acontecimentos, que esquivem o controle consensual; dobras cerebrais renovadas, saídas inusitadas para a vida, possibilidades antropológicas inéditas, ainda que pequenas ou frágeis, conformadoras de linhas criativas de fuga, de derivação ou de resingularização. Eis o que assemelha Filosofia e Arte. Relançar possíveis: tal seria a profunda significação da filosofia hoje e a sua secreta comunhão com as artes, com a vontade criadora em geral. 
Nessa perspectiva, pensar já não mais será uma simples questão de teoria, mas de vida, de estilo de vida implicado; em outras palavras, o critério da teoria já não será teórico. Razão porque Deleuze entende propor uma pragmática filosófica que enderece a seus objetos perguntas do tipo: Que modo de existência isso implica? Que possibilidades de vida aí se abrem ou se fecham? Na filosofia deleuziana nada suscita um problema de significação e de interpretação, nem mesmo os conceitos como signos filosóficos. Nada há a interpretar, mas tudo a experimentar; tudo deverá fazer sentido (ou não) unicamente por sua fecundidade do ponto de vista das nossas experimentações. Reiteradas vezes Deleuze exorta a que se experimente, que se estimem os efeitos. "Os conceitos são exatamente como sons, cores ou imagens, são intensidades que nos convêm ou não, que passam ou não passam". Para que passem, cumpre "apagar, limpar, laminar, ou até mesmo rasgar para fazer passar uma corrente de ar vinda do caos que nos traz a visão". 6 Singular protocolo, que se cumpre nos aplats de Bacon - lugar de todas as variações rítmico-cromáticas - tanto quanto nos conceitos capazes de fissurar as "belas interioridades orgânicas", de abrir buracos "no muro das significações dominantes". ${ }^{7} \mathrm{Em}$ ambos, no conceito e na forma, haverá a mesma intenção de compor por "catástrofe", por "conflagração" 8 ... por variações alotrópicas.

Por força do quê cumprirá rever o valor que comumente se dá ao termo "sentido". A respeito, lê-se em saborosa passagem:

\begin{abstract}
Estamos trespassados de palavras inúteis, de uma quantidade demente de falas $e$ imagens. A besteira nunca é muda nem cega. De modo que o problema não é mais fazer com que as pessoas se exprimam, mas arranjar-lhes vacúolos de so1idão e de silêncio a partir dos quais elas teriam, enfim, algo a dizer. As forças repressivas não impedem as pessoas de se exprimir, ao contrário, elas as forçam a se exprimir. Suavidade de não ter nada a dizer, direito de não ter nada a dizer; pois é a condição para que se forme algo raro ou rarefeito, que merecesse um pouco ser dito. Do que se morre atualmente não é de interferências, mas de proposições que não têm o menor interesse. Ora, o que chamamos de sentido de uma proposição é o interesse que ela apresenta, não existe outra definição para o sentido. Ele equivale exatamente à novidade de uma proposição. Podemos escutar as pessoas durante horas: sem interesse ... Por isso é tão difícil discutir, por isso não cabe discutir, nunca. Não se vai dizer a alguém: "o que você diz não tem o menor interesse". Pode-se dizer: "está errado". Mas o que alguém diz nunca está errado, não é que esteja errado, é que é bobagem ou não tem importância alguma. É que isso já foi dito mil vezes. As noções de importância, de necessidade, de interesse são mil vezes mais determinantes que a noção de verdade. ${ }^{9}$
\end{abstract}

Com o que desregular a balança de valores de qualquer filisteu da filosofia. O mais notável dessa perspectiva está no fato de se sustentar da imagem moderna que o pensamento faz de si. Imagem perturbadora. Sinteticamente:

A primeira característica da moderna imagem do pensamento talvez seja renunciar completamente à relação do pensamento com o verdadeiro, para considerar que a verdade é somente o que o pensamento cria: pensamento é criação e não vontade de verdade, como Nietzsche bem soube fazer entender. Mas se não há vontade de verdade, contrariamente ao que aparecia na imagem clássica, é porque o pensamento 
constitui uma simples 'possibilidade' de pensar, sem definir ainda um pensador que fosse 'capaz' de fazê-lo e pudesse dizer Eu: que violência terá de se exercer sobre o pensamento para que nos tornemos capazes de pensar, violência de um movimento infinito que simultaneamente nos desapossa do poder de dizer Eu? [...] Mas, se há assim uma 'Impotência' do pensamento que permanece no seu cerne [...] é o pensamento enquanto tal que começa a ter rictos, rangidos de dentes, gagueiras, glossolalias, gritos que o obrigam a criar, ou a experimentar. E se o pensamento procura, não é tanto à maneira de um homem que pudesse dispor de um método, mas antes como um cão que desse saltos desordenados [...]. ${ }^{10}$

Como querer que aquele que vive de recognições identifique-se com tal imagem animalesca (histérica?) do pensamento? Como fazê-lo entender que o pensamento moderno há tempos se identificou com a prática do artista mais caótico? Bacon, Deleuze dirá, é de uma violência, de uma intempestividade exemplares. Bacon dá saltos no lugar. Com os quais conquista o estilo da variedade, da multiplicidade, da intensidade. E, sobretudo, Bacon grita... Seu estilo é um modo de transferir a confusão e a violência da vida animal para o plano mental de uma multiplicidade de significações. Multiplicidade caótica, intensa, que de fato não se inscreve tanto em um plano mental - feito de encadeamentos racionais - quanto em um plano nervoso - feito de conexões e hiatos imponderáveis. Multiplicidade afeita à "nervosidade", é o lugar onde o pensamento "traça no cérebro sulcos desconhecidos, torce-o, dobra-o, fende-o". 11

De fato, a pintura de Bacon entende investir diretamente contra o sistema nervoso à força de imagens a fim de fissurá-lo. Deleuze vê nisso a possibilidade de "liberar a vida ali onde ela está aprisionada, traçar linhas de fuga". ${ }^{12} \mathrm{~A}$ intenção é de peso para o pensador das linhas. Linhas de segmentarização, linhas quebradas, linhas de demolição, linhas de derivação, indefectivelmente linhas de ruptura e fuga: toda uma cartografia de intensidades concorre em Deleuze a "fazer alguma coisa fugir, fazer um sistema vazar como se fura um cano". ${ }^{13} \mathrm{O}$ mais elevado objetivo do pensamento também o é da arte. "Faça a linha e nunca o ponto!", conclama o filósofo em sua escrita por slogans. "A velocidade transforma o ponto em linha! Seja rápido, mesmo parado! Linha de acaso, jogo de cintura, linha de fuga. Nunca suscite um General em você! Nunca idéias justas, justo uma idéia". ${ }^{14}$

Há, de fato, uma profusão de linhas em Bacon. Sobretudo uma linha diagramática, meridional, bizantina, linha de catástrofe, ou melhor, de catastrófica nervosidade, comandada por uma geometria da ablação, da adjunção, da projeção, da intersecção ${ }^{15}$, que explica como nele um "pessimismo figurativo" cede a um "otimismo nervoso". ${ }^{16} \mathrm{O}$ estilo é capaz de cavar no homogêneo "diferenças de potenciais" entre as quais alguma coisa pode passar, pode se passar. Algo que ganha intensidade, movimento, e que "define o funcionamento da pintura" e, por analogia, o funcionamento do pensamento moderno.

É uma inquietante complacência, se não um constrangimento, que perde fôlego aqui. Lêse em Différence et Répétition: 
Como diz Nietzsche, a Verdade parece ser uma criatura bondosa que ama suas comodidades, que dá, sem cessar, a todos os poderes estabelecidos a certeza de que jamais causará o menor embaraço a alguém, pois ela, definitivamente, é apenas a ciência pura ... Que é um pensamento que não faz mal a ninguém, nem àquele que pensa, nem aos outros? O signo da recognição celebra esponsais monstruosos em que o pensamento "reencontra" o Estado, reencontra a "Igreja", reencontra todos os valores do tempo que ela, sutilmente, fez com que passassem sob a forma pura de um eterno objeto qualquer, eternamente abençoado. Quando Nietzsche distingue a criação de valores novos e a recognição de valores estabelecidos [...] trata-se, na verdade, de uma diferença formal e de natureza. O novo permanece para sempre novo, em sua potência de começo e de recomeço, como o estabelecido já estava estabelecido desde o início, mesmo que tivesse sido preciso um pouco de tempo empírico para reconhecê-lo. O que se estabelece no novo não é precisamente o novo, pois o próprio do novo, isto é, a diferença, é provocar no pensamento forças que não são as da recognição, nem hoje, nem amanhã, potências de um modelo totalmente distinto, numa terra incognita nunca reconhecida, nem reconhecível. E de que forças vem ele ao pensamento, de que má natureza e de que má vontade centrais, de que desmoronamento central que despoja o pensamento de seu "inatismo" e que a cada vez o trata como algo que nem sempre existiu, mas que começa, constrangido e forçado? ${ }^{17}$

A análise denota o risco de se tomar os objetos através de atos de recognição. $O$ pensamento e todas as suas faculdades podem neles encontrar pleno emprego; o pensamento pode neles ocupar-se, mas esta ocupação e este emprego não têm nada a ver com pensar. Acontece de o pensamento ser aí preenchido apenas por uma imagem de si mesmo, imagem em que ele se reconhece tanto mais quanto reconhece as coisas: "é um dedo, é uma mesa, bom dia Teeteto". ${ }^{18}$

Ora, sustenta Deleuze, "é quando não se reconhece, quando se tem dificuldade em reconhecer, que se pensa verdadeiramente"..$^{19}$ É preciso uma "violência original" feita ao pensamento, uma "estranheza", uma "inimizade", de maneira a tirá-lo de seu estupor natural ou de sua eterna possibilidade: nada pressupõe a filosofia, tudo parte de uma misosofia. Não se pode, pois, contar com o pensamento para fundar a necessidade relativa do que ele pensa: deve-se contar, antes, com a contingência de um encontro com aquilo que força a pensar, a fim de se estabelecer a necessidade absoluta de um ato de pensar, do que Deleuze chama uma "paixão de pensar".

Ora, quem pensa com paixão e por paixão é propriamente o artista. Há no mundo algo que força a pensar. E que é encontrado sob tonalidades afetivas diversas, admiração, ódio, amor, dor, isto é, dimensões "vividas" envolvendo novas possibilidades de ver e de sentir que dão ao pensar sua necessária compreensão não-filosófica, antes experimental que abstrata. A paixão, condição de modernidade para o pensamento, é veículo de uma intensidade que é pura diferença em relação a si, fenda de si. Para Deleuze, quem pensa modernamente é um "Eu rachado", coagido a pensar aquilo que só pode ser pensado como sempre outro, aquilo que envolve diferenciais de pensamento e que somente significa a mais alta potência de pensar à força de também designar o impensável ou a impotência de pensar. 
A modernidade desperta assim para uma impotência interna do pensamento, para sua consciência de que pensar se faz sobretudo contra o próprio pensamento, contra essa fenda interior que faz com que as idéias, surgidas em infinita rapidez, percam velocidade, passem a exigir parcas dobras cerebrais e, por fim, escapem. Nesse tocante, as imprecações deleuzianas contra os tempos presentes não fazem senão prosseguir Heidegger.

Não, nós não pensamos, não aprendemos ainda a pensar, ainda não sabemos o que pensar significa, o pensamento permanecerá em nós uma possibilidade irrealizada enquanto não se der por tarefa o que eminentemente dá o que pensar. ${ }^{20}$

O que dá a pensar, complementaria Deleuze, é o que faz viajar o pensamento, o que o torna móvel ${ }^{21}$, de um movimento sinuoso, reptilíneo ${ }^{22}$; o que dele faz uma máquina de traçar novos circuitos neurobiológicos, afetivos, perceptivos, novos modos de idear e sentir em velocidade/intensidade incompatíveis com as cristalizações dos circuitos mentais impostas pelos atuais conformismos e consensos.

Está-se aqui, é evidente, insinuando que a pintura de Bacon, deleuzianamente interpretada, dá o que pensar na exata medida em que desconcerta nossas faculdades sensitivas há muito postas em funcionamento regrado. Mas, mais que isso, Bacon dá o que pensar porque o que ali faz imagem é da ordem de uma intensidade que se produz no plano mesmo da sensibilidade, como modo de levá-la a seu limite. De fato,

[...] enquanto o pensamento permanece no pressuposto de sua boa natureza e de sua boa vontade, sob a forma de um senso comum, de uma ratio, de uma cogitatio natura universalis, ele nada pensa, prisioneiro da opinião, imobilizado numa possibilidade abstrata [...] O pensamento só pensa coagido e forçado, em presença daquilo que 'dá a pensar', daquilo que existe para ser pensado - e o que existe para ser pensado é do mesmo modo o impensável ou o não-pensado, isto é, o fato perpétuo que 'nós não pensamos ainda'. É verdade que, no caminho que leva ao que existe para ser pensado, tudo parte da sensibilidade. Do intensivo ao pensamento, é sempre através de uma intensidade que o pensamento nos advém. $O$ privilégio da sensibilidade como origem aparece nisto: o que força a sentir e aquilo que só pode ser sentido são uma mesma coisa no encontro, ao passo que as duas instâncias são distintas nos outros casos. Com efeito, o intensivo, a diferença na intensidade, é ao mesmo tempo o objeto do encontro e o objeto a que o encontro eleva a sensibilidade. Não são os deuses que são encontrados; mesmo ocultos, os deuses não passam de formas para a recognição. $\mathrm{O}$ que é encontrado são os demônios, potências do salto, do intervalo, do intensivo ou do instante, e que só preenchem a diferença com o diferente; eles são os porta-signos. E é o mais importante: da sensibilidade à imaginação, da imaginação à memória, da memória ao pensamento - quando cada faculdade disjunta comunica à outra a violência que a leva a seu limite próprio - é a cada vez uma livre figura da diferença que desperta a faculdade, e a desperta como o diferente desta diferença. ${ }^{23}$

Para Deleuze, Bacon é, em pintura, a evidência de uma "livre figura da diferença". Para entendê-la, ou melhor, para senti-la, é preciso "esburacar" certas evidências. 
Ao se percorrer a obra de Bacon, sob os auspícios do sensacionismo acima relatado, questões se avolumam: Que significam esses personagens em convulsão? De que catástrofe parecem acometidos? O que dizem, o que anunciam? De que experiência essas aparições espasmódicas dão conta? E, sobretudo, que "queda" é essa onipresente, desses corpos-blocos-de-cores, que despencam de suas armaduras orgânicas e que parecem com isso ditar o ritmo mesmo da pintura? ${ }^{24}$

Para julgar Bacon invariavelmente são acionados clichês: sua pintura acumularia imagens de violência, angústia, tortura, fechamento, agonia; ela exprimiria, por assim dizer, o intolerável da condição humana. As palavras mais repetidas para comentá-la são: horror, dor, repulsa, carnificina, mal-estar, náusea, inferno, desespero.

Philippe Sollers, autor de um percuciente texto sobre Bacon, entende que "uma pintura é muitas vezes julgada horrível porque é direta. Ela comprova um sono da razão naqueles que a acham monstruosa, ao passo que Bacon mostra como o despertar dos monstros metamorfoseou a razão". ${ }^{25}$ Acontece de comumente se rechaçar essa outra razão. Acontece, constata Sollers, de sermos "intoxicados bem-pensantes, 24 horas por dia, pela imagerie planetária". Não se entende que a pintura pode ser uma linguagem universal no turbilhão das imagens, na direta contrafação de toda idéia ilustrativa. Bem como um "longo, imenso e arrazoado desregramento de todos os sentidos". Sollers explica:

O quadro aí está: não se sente mais que o vemos; apalpamo-lo, escutamo-lo. Ele não conta uma história, vai direto ao sistema nervoso. E, no entanto, percebemos bem um acontecimento figurado, um drama em relance, um grito, uma crucifixão, um vômito, uma agressão, [uma defecção], uma dilaceração. Ser ou não ser, isto é, se representar ou não se representar, tal é a questão. ${ }^{26}$

O que, afinal, "aí está", manifesto? A imagem estupefaciente do novo pensador, no Tríptico de 1972 da Tate Gallery ou ainda em Three figures in a room de 1964 ${ }^{27}$ : personagem recolhido em seu isolamento, amoldado à sua cadeira de "sonâmbulo em vigília", a seu vaso sanitário, a seu lavabo. A figura agarra o fundo em lugar de nele se diluir; ela não existe, porém, sem esse fundo que a deixa ser mensurando-lhe sua temporalidade como variação cromática dos tons quebrados de sua figura. ${ }^{28} \mathrm{~A}$ peça é circular, mas como que situada em parte alguma. O lavabo é fixado ao muro que já é o solo. A lâmpada pende de um teto que, talvez, não exista. O pensador, aliás, não está só: sua sombra se perfila como seu alter animal, continuação do fundo negro de um dentro que não parece ter nenhum fora. Tudo o que se apresenta como dentro tem a aparência completamente fora. Não há mais dentro que fora, mas somente uma espacialização continuada, de vibração espasmódica. O ser-aí não tem garantido seu sentido metafísico, conclui Sollers. "Bacon pinta o heroísmo, perfeitamente gratuito e insólito, do ser-aí. Tragédia, talvez, mas sem patética, a violência por ela mesma em toda a serenidade, como uma lei". ${ }^{29}$ 
Michel Leiris sustenta em algum lugar que as obras de Bacon "ajudam a sentir o que para um homem sem ilusões é o fato de existir". Na verdade, se essa é a sua virtude, é porque Bacon arranca a imagem de seu ilusionismo falsificador. Protocolo de reconquista para a visão do terreno perdido para a foto, que "tende a esmagar a sensação em um único nível " ${ }^{30}$ Deleuze ressalta seu caráter árduo:

Estamos cercados de fotos que são ilustrações, de jornais que são narrações, de imagens-cinema, de imagens-TV. Há clichês psíquicos tanto quanto físicos, percepções já prontas, lembranças, fantasmas. Há uma experiência muito importante para o pintor: toda uma categoria de coisas que se pode chamar 'clichês' ocupa de antemão a tela, antes de se começar. É dramático [...] E se o pintor se contenta em transformar os clichês, em deformá-los ou maltratá-los, em torturá-los em todos os sentidos, essa ainda é uma reação demasiado intelectual, demasiado abstrata, que deixa o clichê renascer de suas cinzas, que deixa ainda o pintor no elemento dito clichê, ou que não lhe dá outra consolação que a paródia. ${ }^{31}$

A advertência é de peso em uma passagem que termina por fazer jus ao mundo representacional ao admitir que "a maçã de Cézanne é muito importante, mais importante que a idéia de Platão".

O que faz então o artista por excelência, o que faz Bacon? "Estivemos quase sempre atrás das telas", diz ele, consciente do multissecular ilusionismo da representação. "Uma existência velada por telas". No limite, tratar-se-ia apenas de levantar a tela, o muro das representações correntes. "Não digo absolutamente nada", somente "figuras surgindo de sua própria carne". Por toda parte, a imagem é falsa. Portanto, é preciso contornar a representação, tomar conta do espaço asfixiado da tela, torná-la irredutível à força de "contra-imagens imediatas", "sem que o cérebro intervenha". ${ }^{32}$ Deleuze insiste em tal reforma da imagem. Trata-se de um espetáculo contra o espetáculo, de um conjunto de imagens trabalhadas contra as imagens. $\mathrm{O}$ que faz imagem em Francis Bacon parece ser o que justamente explica sua dissipação: uma intensidade que ela somente desvela ao se dar como queda da forma tornada acidente. Razão, pois, para tratar na pintura de Bacon da preterição das formas em favor das forças. A imagem concentra ali um potencial de "desordenada convulsão". Ela anuncia, assim, que todo corpo que representa - carne que despenca dos ossos ${ }^{33}$ - se sustém do esgotamento da própria possibilidade narrativa. Desorganização do corpo (sua maior "espiritualidade" ${ }^{34}$ ), informalidade da imagem (sua maior força).

Sollers é facecioso ao falar a respeito:

Como um foguete, o quadro conta ferozmente o arrancamento de sua própria força de contar [...]. Bacon, cosmonauta da nova fase histórica da representação, lança um satélite anti-receptor/transmissor, um analisador/moedor da nebulosa espetacular, uma contra-internet de ponta. A informação, comprimida, dissolve-se. A paixão ressurge. ${ }^{35}$

Com o que concordaria Deleuze. De fato, se na "imensa acumulação de espetáculos, tudo o que era diretamente vivido afastou-se em uma representação" (Debord); se "as 
imagens que se destacaram de cada aspecto da vida fundem-se em um curso comum onde a unidade dessa vida não mais pode ser restabelecida" ${ }^{\prime 6}$, o restabelecimento acrobático operado por Bacon soa como o desafio e a dilaceração de um grito no sufocamento geral. Você quer pintar o horror, perguntam-lhe? Não, objeta Bacon, não o horror, o grito. E por que o grito? Porque "as forças que fazem o grito [...] não se confundem de modo algum com o espetáculo visível diante do qual se grita [...]". Porque à pintura está reservada a função de "acoplar a força sensível do grito e a força insensível do que faz gritar". ${ }^{37} \mathrm{O}$ que explica por que o pessimismo cerebral, que não vê senão os horrores do mundo a ilustrar, cede lugar a um otimismo nervoso, isto é: à evidência de que a figuração visível é secundária em pintura; que o que de fato faz imagem é a violência da sensação mais que aquela do espetáculo.

Evidentemente, esta é uma pintura que volta a arriscar. Uma pintura capaz de refazer o verdadeiro em uma época de "aceleração, de devastação e de inanidade, dilúvio anestésico de imagens reprimindo a possibilidade de pensar". ${ }^{38}$

Tratar-se-ia, pois, de fazer sair a verdade dessa força de ocupação, de golpeá-la na cabeça. Tratar-se-ia de "pintar a tortura da cabeça, seu grito, seu esburacamento, quando ela experimenta a maneira ditatorial com que é fechada e comprimida". ${ }^{39}$ Eis o que Bacon experimenta: "abrir as válvulas da sensação"; atingir diretamente o sistema nervoso; criar imagens pungentes, mesmo se para tanto for preciso reinvestir a piedade humana. Os bons sentimentos pululam sobre fundo de massacres transmitidos ao vivo? A pintura mostrará o que neles há de verdadeiro. O escorchamento aplicado monstruosamente à forma humana é nosso cotidiano visual? Mas outra coisa é senti-lo intensamente. Do contrário, o homem será apenas uma imagem pia amedrontada diante dos filmes e fotos de horror. Deleuze denota com justeza que o conformismo percebe sempre uma foto em lugar de um quadro, que a imagem deixada por si, desde Debord sabemos disso, colabora com nossa cumplicidade para com os carrascos. Donde a necessidade, o interesse - para invocar uma vez mais as novas parametrias deleuzianas - de "abrir válvulas de sensação".

Nisso tudo, que se trate na pintura de Bacon do que Deleuze chama "matter of facts", em lugar de relações inteligíveis (entre objetos ou idéias), é o que resta a verificar para entender como em uma obra que conjura todo modelo a representar, toda história a contar, "alguma coisa se passa que define o funcionamento da pintura".

É todo o desafio que se dá o filósofo, a fim de esclarecer "o que se passa" (isto é, o que ocorre, o acontecimento) em um pintor muito particular que, entre outras características, nutre um belíssimo fantasma demiúrgico: "meu ideal seria de pegar um punhado de tinta e de jogá-lo sobre a tela, com a esperança que o retrato se fizesse ali!". ${ }^{40}$ Ideal do "quadro único que anularia todos os outros". O imediatismo, o acaso: após o que 
veremos... A pintura é um acidente, o homem é um acidente. Se soubermos para onde ir, é porque nos deixamos fechar na ilustração, em uma história a reconhecer. Falência do intérprete. Apanágio do artista, que lembra existir somente acaso "manipulado". ${ }^{41}$

Face a tal demiurgia, vem muito a propósito Deleuze, autor particularmente sensível à questão: "o que passa e o que bloqueia?". O que passa e o que não passa, o que faz passar e o que impede de passar? Sabedor que "somente as intensidades passam, circulam". ${ }^{42}$ É por força delas que as figuras em Bacon cederão finalmente lugar à Pura Força, trânsito que Deleuze acompanha em seu livro e que the define a linha dorsal da argumentação.

Face aos "escorchados" de Bacon é forçoso constatar: "é no corpo que algo se passa". ${ }^{43}$ É no corpo que se farão passar intensidades, ele que as produzirá e as distribuirá em um spatium ele mesmo intensivo, não extenso. ${ }^{44}$ Para que a Arte seja capaz de "furar o encanamento da consciência"; para que ela seja capaz de reatar com a multiplicidade que a percepção é obrigada a filtrar de modo a estar de acordo com o senso comum; para que nela se encontrem condutos de derivação, linhas de fuga pelas quais fazer correr a percepção até um deserto de direções multivariadas; enfim, para que o corpo seja uma experiência susceptível de fissurar a filtragem corrente da consciência, é preciso desorganizá-lo, arrancá-lo à sua organicidade. É preciso que, ao acaso das sensações e dos espasmos, as superfícies se ponham a torcer carregando as figuras sobre suas linhas de histeria, de modo a liberar novos perceptos. É preciso produzir um ritmo que passe do macrométrico ao micrométrico, uma variação sobre a qual se encadeiem posturas divergentes - o que define, igualmente, o plano de um conceito. Razão porque Deleuze sustenta que a forma em Bacon se põe a dizer o acontecimento e não mais a essência, a modulação e não mais a substância, o devir e não mais o ser.

O acontecimento aqui: o de desacreditar a linguagem abrindo buracos para deixar escoar algo, isto é, precisamente aquilo que a oficialidade vigente evita ao cobrir, ao preencher, ao entulhar de um tráfico encarniçado de identidades e declarações fechadas. O acontecimento aqui: o de abrir buracos para deixar escoar o abismo através das figuras, até uma capacidade de captar forças mudas como a Duração, a Intensidade.

Deleuze entendeu perfeitamente que toda a obra de Bacon é a tentativa de captar forças que atravessam a figura humana. Captar forças, isto é, tornar visíveis forças que não o são e, conseqüentemente, dar a ver o que a figuração ou a narração são incapazes de mostrar. Nos circuitos de derivação criados pelo spatium artístico tudo se põe a coexistir segundo uma migração intensa que desce uma linha de delírio onde tudo se avizinha. Viagem em intensidade de um corpo-sem-orgãos onde não há mais um Eu como personagem soberano, mas um conjunto de percursos e de discursos tomados em uma rede disjuntiva de singularidades: experimentação perigosa conduzindo o sujeito residual a um naufrágio, onde aflora o continuum de suas intensidades. 
Deleuze fala de CsO (o corpo des-organizado, de órgãos temporários), conceito retido de Artaud. Em Mille Plateaux, ele é peremptório: encontrar seu CsO, saber fazê-lo, "é uma questão de vida ou de morte, de juventude e de velhice, de tristeza e de alegria. É aí que tudo se decide". O corpo paranóico, o corpo esquiso, o corpo drogado, o corpo masoquista, são tantas experimentações de desorganização do corpo próprio: "Onde a psicanálise diz: pare, reencontre o seu eu, seria preciso dizer: vamos mais longe, não encontramos ainda nosso $\mathrm{CsO}$, não desfizemos ainda suficientemente nosso eu." ${ }^{45}$

Ao contrário da psicanálise, que traduz tudo em fantasma, no conjunto de significâncias e subjetivações, trata-se na arte de retirar o que conserva nos "segredinhos" para transparecer o que literalmente esgarça. Trata-se de retirar a alimentação, a coagulação, a sedimentação que impõem formas, funções, ligações, organizações dominantes e hierarquizadas: "Desfazer o organismo [é] abrir o corpo a conexões que supõem todo um agenciamento, circuitos, conjunções, superposições e limiares, passagens e distribuições de intensidade, territórios e desterritorializações medidas à maneira de um agrimensor". ${ }^{46}$

Logique de la Sensation ressalta algumas imagens de produção de um CsO pictórico em Bacon: aquelas do Tríptico de 1972, dos Three studies for portrait of George Dyer (on lightground) de 1964, ou ainda dos Three studies of Isabel Rawsthorne de $1968{ }^{47}$

\begin{abstract}
A extraordinária agitação dessas cabeças não vem de um movimento que a série seria instada a recompor, mas antes de forças de pressão, de dilatação, de contração, de achatamento, de estiramento, que se exercem sobre a cabeça imóvel. São como forças enfrentadas no cosmos por um viajante trans-espacial imóvel em sua cápsula. É como se forças invisíveis sacudissem a cabeça sob os ângulos mais diversos. E aqui as partes limpas, varridas, do rosto tomam um novo sentido, pois que elas marcam a zona mesma onde a força está golpeando [...] Quando uma força se exerce sob uma parte limpa, ela não faz nascer uma forma abstrata, muito menos ela combina dinamicamente formas sensíveis: ao contrário, ela faz dessa zona uma zona de indiscernibilidade comum a várias formas, irredutível a umas como a outras, e as linhas de força que ela faz passar escapam a toda forma por sua própria nitidez, por sua precisão deformante. ${ }^{48}$.
\end{abstract}

"Todo o corpo é percorrido por um movimento intenso. Movimento disformemente disforme, que reporta a cada instante a imagem real sobre o corpo para constituir" ${ }^{49}$ : o que Deleuze chama a Figura. Esta é corpo atravessando ordens sensíveis sobrepostas, segundo posturas que o torcem e retorcem sob a violência de variadas forças e variados tensores. A Figura se substitui assim a toda descrição do processo de um organismo tomado no desenvolvimento de sua história. Não se pergunta como um corpo se move em largura e em comprimento, mudando seus gestos e sentimentos. Pergunta-se como um corpo se move em profundidade - em uma "escala intensiva" que o torna cada vez mais íntimo de sua carnalidade..$^{50}$

A sensação - vis elastica ${ }^{51}$ - é o teatro de uma metamorfose, de uma crueldade, onde se joga uma única figura sobre níveis sensitivos dessemelhantes. Há graus de queda, de 
curvatura ou de dilatação, forças que se exercem sobre o corpo segundo um ritmo que Bacon procura tornar visível. Essa visibilidade, que toma o corpo por sua profundidade tocando as dimensões que contraem ou dilatam, deixa de ser narrativa. A narração se desenvolve somente sobre um nível de sensação. Entre as figuras, ela tece relações comensuráveis. Não há perigo nisso. Ao contrário, tornar visível o movimento do corpo sobre si mesmo através dos níveis inorgânicos da sensibilidade, seguir a peregrinação do CsO - um corpo cujos órgãos não são essência, mas acontecimento -, eis o que é arriscado em pintura. Pois que a torção desses corpos até seu irreconhecimento leva-os ao limite da organização normal de nossas faculdades, acomodadas ao dispositivo da recognição.

As figuras que Bacon libera executam o que Deleuze chama "um salto no lugar, uma deformação no lugar"; hiperestesias e enrijecimentos são ali - como nos trípticos acima mencionados - marcados por zonas limpas, varridas, e as anestesias e paralisias por zonas ausentes. Mutilações e próteses prestam-se a um jogo de valores retirados ou acrescentados. O corpo traduz-se em conjunto de "sonos" e "vigílias" histéricas afetando suas várias partes. ${ }^{52}$ Convulsionado, ele tende ao informe como seu estado, diga-se, mais íntimo. Cabeça como buraco aberto na carne urrante, na Crucifixão de 1950, ou, procedimento mais radical, aglomerado sanguinolento por onde escoa o corpo inteiro, no painel central do tríptico Sweeney Agonistes. ${ }^{53}$

Deleuze interessa-se pelos modos como um conjunto visual provável é desorganizado, deformado por traços manuais livres que tornam a figura visual improvável. ${ }^{54} \mathrm{O}$ improvável como o que é extraído do "conjunto das probabilidades figurativas". ${ }^{55} \mathrm{O}$ improvável, contrafação do clichê, como efeito do que se estende entre espaços irredutíveis, como efeito da peregrinação de uma forma sobre uma variedade a $n$ dimensões. Por exemplo, uma boca:

prolongamo-la, fazemos com que ela vá de um extremo a outro da cabeça. Por exemplo, a cabeça: limpamos uma parte com uma brocha, uma vassoura, uma esponja ou um pano. É o que Bacon chama um Diagrama: é como se, de repente, introduzíssemos um Saara, uma zona de Saara, na cabeça [... ${ }^{56}$

Emaranhar as linhas figurativas, prolongando-as, tornando-as por assim dizer histéricas, isto é, induzindo entre elas novas distâncias, novas relações, permite aceder a uma semelhança não-figurativa: "semelhança mais profunda onde não se pode mais discernir órgãos, olhos, nariz ou boca". ${ }^{57} \mathrm{O}$ contorno cede aqui a uma linha diagramática, aquela do "deserto-distância" ${ }^{2}$; as superfícies são sobreinvestidas pelos significantes e significados, o que virtualiza a imagem pictórica. O olhar é convidado a um percurso nômade que mergulha no diagrama sensorial das curvaturas e ao longo do qual um rosto expande sua boca, se enche e se modifica como um balão enrugando sob a torção de seus pólos. 
A realidade é assim tomada em seu intenso movimento. Não se trata de ilustrar, ressalta incessantemente Deleuze, mas "de encarnar o movimento na matéria, e é o movimento da matéria que dá o movimento do sujeito". Que um corpo visível enfrente "como um lutador, as potências do invisível": eis o triunfalismo da pintura.

Quando a sensação visual enfrenta a força invisível que a condiciona, então ela libera uma força que pode vencer esta, ou fazer dela uma amiga. A vida grita para a morte, mas justamente a morte não é mais aquele traço demasiado visível que nos faz fraquejar, ela é essa força invisível que a vida detecta, desaloja e faz ver gritando. É do ponto de vista da vida que a morte é julgada, e não o inverso, onde nós nos comprazíamos. Bacon [...] faz parte desses autores que podem falar em nome de uma vida mais intensa, por uma vida mais intensa. Não é mais um pintor que 'acredita' na morte. Todo um miserabilismo figurativo, mas a serviço de uma Figura da vida cada vez mais forte [...] Elevou Figuras indomáveis, indomáveis por sua insistência, por sua presença, no momento mesmo em que 'representava' o horrível, a mutilação, a prótese, a queda ou o fracassado. Deu à vida um novo poder de rir extremamente direto. ${ }^{59}$

Ora, para suscitar renovados humores, Bacon paradoxalmente necessita dar a ver a Figura em uma espécie de queda: sua visibilidade se salva por um triz da dissipação no $a p l a t^{60}$, tomada que é em uma espécie de escoamento que a pintura põe em cena.

O primado em Bacon é dado à descida. Bizarramente, o ativo é o que desce, o que cai. O ativo é a queda, mas isso não é forçosamente uma descida no espaço, em extensão. É a descida como passagem da sensação, como diferença de nível compreendida na sensação [...], a carne desce dos ossos, o corpo desce dos braços ou das coxas. A sensação se desenvolve por queda, caindo de um a outro nível. A idéia de uma realidade positiva, ativa, da queda é aqui essencial. ${ }^{61}$

A queda tem a ver com o modo de funcionamento do Diagrama. Lemos, uma vez mais: "algo se passa que define o funcionamento da pintura". Veja-se, a propósito, a obra Painting de 1946. ${ }^{62}$ Bacon queria "fazer um pássaro pousando no campo", mas os traços ganham uma espécie de independência e passam a sugerir algo de totalmente diferente, o homem com um guarda-chuva. Não é simplesmente dizer que o Diagrama faz passar de uma forma a outra. Ele é, antes, uma série de acidentes sobrepondo-se uns aos outros.

Se se parte do pássaro como forma figurativa intencional, vê-se o que corresponde a essa forma no quadro, o que the é de fato análogo, não é a forma-guarda-chuva (que definiria somente uma analogia figurativa ou de semelhança), mas é a série ou o conjunto figural que constitui a analogia propriamente estética. Os braços da carne que se elevam como análogos como a asas, as fatias de guarda-chuva que caem e se fecham, a boca do homem como um bico deitado. Ao pássaro, foram substituídos, não uma outra forma, mas relações bastante diferentes, que engendram o conjunto de uma Figura como o análogo estético do pássaro (relações entre braços da carne, fatias do guarda-chuva, boca do homem). O diagrama-acidente embaralha a forma figurativa intencional, o pássaro: ele impõe manchas e traços informais, que funcionam somente como traços de passaridade, de animalidade. E são esses traços não figurativos donde, como de uma poça, sai o conjunto de chegada, e que, para além da figuração própria a esse conjunto por sua vez, elevam-no à potência de pura Figura. ${ }^{63}$ 
Donde a "semelhança mais profunda" de que fala Deleuze, semelhança não-figurativa: Imagem figural. Para esta cumpre, aliás, reter a advertência de Bacon: é uma imagem de risco; a linha diagramática, ao induzir novas distâncias entre as formas, arrisca sempre perder a imagem que se quer, através de sua deformação cada vez mais pungente (candente?). Pois, "sendo ele próprio uma catástrofe, o diagrama não deve fazer catástrofe. Sendo ele próprio zona de emaranhamento, não deve emaranhar o quadro [...] O essencial do diagrama é que ele é feito para que algo dele saia, e ele fracassa se nada dele sair". ${ }^{64}$

O diagrama sustém a sensação em seu trânsito caótico; ela não é em si puro caos, mas germe de ordem, salvaguarda da linha que impede a catástrofe total da composição. ${ }^{65}$ Que não se arrisque, pois, na intenção de surpreender o fato - através de muitas formas apreendidas em uma única e mesma Figura, como a Combray de Proust em uma xícara de chá6 ${ }^{6}$-, fornecer o amaneirado, isto é, o corpo-leitura da dor e da angústia. Ao contrário, conclui apologeticamente Deleuze: "esse fato pictural vindo da mão, é a constituição do terceiro olho, um olho háptico, uma visão háptica do olho, uma nova clareza". ${ }^{67}$ A própria filosofia mostra-se inseparável de tal "loucura" do ver que patrocina a decomposição de todas as formas sustentadas por um objetivo modulável. Não the parece inapropriada uma lente óptica onde as praias de cores e sombras se alargam e se comprimem, se agridem ou se encaixam...

A propósito, avalie-se a leitura baconiana que Deleuze propõe do pensamento moderno. Bacon, aquele que faz a "travessia" da história da pintura para mostrar o que o "homem moderno pode ainda esperar dela" 68 , prestar-se-ia a "ilustrar" a imagem moderna do pensamento? Sobretudo no modo como ele entende o ato de pintar. Sobretudo no modo como seus traços "irracionais, involuntários, acidentais, livres, ao acaso", "nãorepresentativos, não-ilustrativos, não-narrativos", "traços de sensações confusas", "traçam marcas que não mais dependem de nossa vontade nem de nossa vista", fazendo assim surgir "um outro mundo", da cegueira, da catástrofe, do caos. ${ }^{69}$

O Diagrama, sendo conjunto operatório de linhas e de zonas, de traços e de manchas asignificantes e não-representantes", tem por função "sugerir", introduzir "possibilidades de fato", que se tornam fato pictural ao dar ao olhar "uma outra potência". O Diagrama é um caos, uma catástrofe, mas também um germe de ordem ou de ritmo ao abrir insuspeitos domínios sensíveis. ${ }^{70}$

Nesse fazer diagramático, o que afinal o artista propõe ao homem moderno?

Para Deleuze, ele exprime perfeitamente o traço essencial que a Arte compartilha com a Filosofia na idade moderna do pensamento. A filosofia hodierna presta-se a exercer o pensar em um nexo nativo com o impensável, a fornecer pensamento ao impensado, a 
tentar atingir um plano irredutivelmente paradoxal que não pode ser pensado e que, todavia, é o que há que pensar: um não-pensável que força a pensar. Donde toda uma violência, uma turbulência sofrida de "dentro", todo um pathos, uma singular patologia, tão estética quanto filosófica. O pensamento moderno é, assim, um flerte com sua fragilidade congênita, intrínseca, uma experimentação no escuro, uma secreta patologia, uma ameaça de afundamento constante no que se pretende dominar. Uma condenação a tatear, a avançar às escuras, a inventar a cada vez a sua orientação, ou a sua "desorientada" experimentação não-subjetiva, os seus caminhos a-metódicos, necessariamente paradoxais.

A questão de Deleuze terá sempre sido aquela de uma imagem material do pensamento onde seguir os rastros desconhecidos, as conexões imprevistas, as novas e insuspeitas sinapses traçadas no cérebro por toda criação de conceitos. Através de dois deles: a Figura e o CsO, Deleuze entende evidenciar essa imagem, entre outros lugares da fatura artística, no paradoxo em Bacon da heterogeneidade da produção e do produto. De fato, o artista entende fazer similitude (a semelhança do retrato) com a dissimilitude, a dessemelhança que implica essa "maneira totalmente ilógica" consistindo em justapor manchas de cor desprovidas de toda capacidade mimética.

Para mim, o mistério da pintura hoje é a maneira pela qual a aparência pode ser dada. Sei que ela pode ser ilustrada, sei que ela pode ser fotografada. Mas como essa coisa pode ser dada de modo tal que o mistério da aparência seja captado no mistério da fatura? É por um método ilógico de fabricação, um meio ilógico de fazer com que, espera-se, será um resultado lógico - no sentido em que se espera que se poderá fornecer de repente presente a coisa de uma maneira totalmente ilógica, mas que ela será totalmente real e que, no caso de um retrato, ali se reconhecerá a pessoa. ${ }^{71}$

Mistério da fatura: fornecer de maneira totalmente ilógica o que obedece a uma lógica da sensação, diga-se, muito pouco lógica.

\footnotetext{
* Osvaldo Fontes Filho é professor de filosofia da PUC/SP.

${ }^{1}$ DELEUZE, G. Francis Bacon. Logique de la Sensation. Paris: Éditions de la Différence, 1996 (reed.), p. 15.

${ }^{2}$ Idem. O que é a filosofia? Tradução de Margarida Barahona e António Guerreiro. Lisboa: Editoral Presença, 1992, p. 31.

${ }^{3}$ Idem. Conversações. Tradução de P. P. Pelbart. Rio de Janeiro: Ed. 34, 1992, p. 174.

${ }^{4}$ Idem. O que é a filosofia? Op. cit., p. 31.

${ }^{5}$ Idem. Diálogos. São Paulo: Editora Escuta, 1998, p. 10.

${ }^{6}$ Idem. O que é a filosofia? Op. cit., p. 178.

${ }^{7}$ Idem. Diálogos. Op. cit., p. 58.

${ }^{8}$ Idem. O que é a filosofia? Op. cit., p. 177.

${ }^{9}$ Idem. Conversações, Op. cit., pp. 161-162.
} 
${ }^{10}$ Idem. O que é a filosofia ? Op. cit., pp. 51-52.

${ }^{11}$ Idem. Conversações. Op. cit., p. 186.

12 Ibidem, p. 176.

${ }^{13}$ Idem. Diálogos. Op. cit., p. 49.

${ }^{14}$ Idem. Mil Platôs: Capitalismo e Esquizofrenia. Vol. 1. Tradução de Aurélio Guerra Neto, Célia Pinto Costa. Rio de Janeiro: Editora 34, 1995, p. 36.

${ }^{15}$ Idem. Logique de la Sensation. Op. cit., p. 34.

${ }^{16}$ Ibidem, p. 31.

17 Idem. Diferença e repetição. Tradução de L. B.L. Orlandi e R. Machado. Rio de Janeiro: Graal, 1988, p. 225.

${ }^{18}$ Ibidem, p. 229. O erro imigra sem traumas para a crítica e a história da arte: "Ah! ei-nos ali, na pintura sombria de Bacon, reconhecidos em nossa tragédia de homens modernos!"

${ }^{19}$ Ibidem, p. 230.

${ }^{20}$ HEIDEGgER, M. Aus der Erfahrung des Denkes. Apud DIAS, S. Lógica do acontecimento. Deleuze e a filosofia. Porto: Edições Afrontamento, 1995.

${ }^{21}$ Cf. DELEUZE, G. Mil Platôs. Op. cit., p. 424.

${ }^{22}$ Idem. O que é a filosofia ? Op. cit., p. 179.

${ }^{23}$ Idem. Diferença e repetição. Op. cit., pp. 238-239.

${ }^{24}$ São exemplares dessa "queda" as Cruxifixions, de 1950, de 1962, de 1965, todas reproduzidas no tomo II de Logique de la Sensation, Op. cit., respectivamente imagens n 52,56 e 58

25 SOLLERS, P. "Les passions de Francis Bacon". In: Éloge de l'infini. Paris: Gallimard-Folio, 2001, p. 74.

${ }^{26}$ Ibidem, p. 75.

${ }^{27}$ Reproduzidos em DELEUZE, G. Logique de la Sensation. Op. cit., tomo II, respectivamente imagens $\mathrm{n}^{\circ} 70$ e 82.

${ }^{28}$ Cf. Ibidem, p. 91.

${ }^{29}$ Ibidem, p. 86.

${ }^{30}$ Ibidem, p. 59.

31 Ibidem, p. 57.

32 Ibidem, p. 28.

${ }^{33}$ Ibidem, p. 54.

${ }^{34}$ Ibidem, p. 34.

${ }^{35}$ SOLLERS, P. Op. cit., p. 84.

${ }^{36}$ Ibidem.

${ }^{37}$ DELEUZE, G. Logique de la Sensation, Op. cit., p. 41.

${ }^{38}$ SOLLERS, P.. Op. cit., p. 91.

${ }^{39}$ Ibidem.

${ }^{40}$ Apud SYLVESTER, D. Entretiens avec Francis Bacon. Genebra : Skira, 1996 (reed.), p. 113.

${ }^{41}$ DELEUZE, G. Logique de la Sensation, Op. cit., p. 61. 
${ }^{42}$ Idem. Mil Platôs. Op. cit., p. 13.

43 Ibidem, p. 16.

44 Ibidem, p. 13.

${ }^{45}$ Ibidem.

46 Ibidem, p. 22.

47 Reproduzidos em DELEUZE, G. Logique de la Sensation. Op. cit., tomo II, respectivamente imagens $n^{\circ} 70,74$ e 72.

48 Ibidem, p. 40.

49 Ibidem, p. 18.

${ }^{50}$ Cf. Ibidem, p. 21.

51 Ibidem, p. 30.

${ }^{52}$ Cf. Ibidem, p. 53.

${ }^{53}$ Reproduzidos em DELEUZE, G. Logique de la Sensation. Op. cit., tomo II, respectivamente imagens $n^{\circ} 52$ e 61.

${ }^{54}$ Cf. Ibidem, pp. 60-62.

55 Ibidem, p. 61.

56 Ibidem, p. 65.

57 Ibidem, p. 100.

58 Ibidem, p. 101.

${ }^{59}$ Ibidem, p. 42.

${ }^{60}$ Ibidem, p. 25.

61 Ibidem, p. 54.

${ }^{62}$ Reproduzido em DELEUZE, G. Logique de la Sensation. Op. cit., tomo II, imagem $n^{\circ} 30$.

63 Ibidem, pp. 100-101.

${ }^{64}$ Ibidem, p. 102.

${ }^{65}$ Cf. Ibidem, p. 71,

${ }^{66}$ Ibidem, p. 46.

${ }^{67}$ Ibidem, p. 103.

${ }^{68}$ Ibidem, pp. 87 e 67.

69 Ibidem, p. 66.

${ }^{70}$ Ibidem, p. 67.

${ }^{71}$ Apud SYLVESTER, D. Op. cit., p. 111. 